\title{
Land Use Suitability Assessment in Low-Slope Hilly Regions under the Impact of Urbanization in Yunnan, China
}

\author{
Gui Jin, ${ }^{1}$ Zhaohua Li, ${ }^{1}$ Qiaowen Lin, ${ }^{2}$ Chenchen Shi, ${ }^{3}$ Bing Liu, ${ }^{4}$ and Lina Yao \\ ${ }^{1}$ Faculty of Resources and Environmental Science, Hubei University, Wuhan, Hubei 430062, China \\ ${ }^{2}$ School of Public Administration, China University of Geosciences, Wuhan 430074, China \\ ${ }^{3}$ State Key Laboratory of Water Environment Simulation, School of Environment, Beijing Normal University, Beijing 100875, China \\ ${ }^{4}$ College of Geomatics, Shandong University of Science and Technology, No. 579 Qianwangang Road, \\ Economic \& Technical Development Zone, Qingdao, Shandong 266590, China \\ ${ }^{5}$ Institute of Geographic Sciences and Natural Resources Research, Chinese Academy of Sciences, Chaoyang District, \\ Beijing 100101, China
}

Correspondence should be addressed to Zhaohua Li; zli@hubu.edu.cn

Received 19 September 2014; Accepted 13 December 2014

Academic Editor: Jinwei Dong

Copyright (C) 2015 Gui Jin et al. This is an open access article distributed under the Creative Commons Attribution License, which permits unrestricted use, distribution, and reproduction in any medium, provided the original work is properly cited.

\begin{abstract}
Nowadays, the conflict between land development and land conservation has become increasingly serious in China. The plan called "town of mountain" is carried out in many nonplain areas to alleviate the conflict. To avoid geological disasters and ecological risks in those areas, land use suitability assessment is of great importance. In this paper, the fuzzy weight of evidence model is applied into land use suitability assessment in low-slope hilly regions in Yunnan, China. Fuzzy weight of evidences is calculated to determine 9 map layers. Finally, posterior probabilities are modified after synthesizing each map layer, which are used to generate a land use suitability map. The results show that $9.33 \%, 26.18 \%, 45.98 \%$, and $18.51 \%$ of low-slope hilly regions are separately highly suitable, moderately suitable, marginally suitable, and unsuitable for development. Besides, highly and moderately suitable areas are mainly located in towns with excellent natural and socioeconomic conditions. The largest areas which are marginally suitable for development are most widely distributed. Unsuitable areas are mainly distributed far away from towns and water sources. The findings of the research will promote the rational use and scientific management of the land.
\end{abstract}

\section{Introduction}

Due to the rapid urbanization in China [1], the demand for built-up land both in urban and rural areas has been dramatically increased with the shrinking of arable land [2-4]. The conflict between land development and land conservation has become increasingly serious [5-8]. Under the most stringent farmland protection system in China, the strategy of developing low-slope hilly regions is carried out to alleviate the conflict [9]. The concept of low-slope hilly regions is put forward under the demand for land resources in mountain area with the social and economic development and urbanization construction. It refers to contiguously distributed land with slopes less than 25 degrees in the majority of hilly areas as well as unused low mountains and hills which can be used by town construction in the mountain area. It mainly includes a variety of reserved land types such as unused land, abandoned garden, and inefficient forest, which are mostly distributed in the regions with little plain and inadequate protection of cultivated land. Currently, there is a shortage of land available for the development of cities and towns in China $[10,11]$. However, low-slope hilly regions account for a relatively large proportion of the available land. Current land use in China, such as a small amount of land per person, intense exploitation of land development, and shortage of reserved land, has limited the development of regional economy and society $[12,13]$. Therefore, it is a good way to alleviate the conflict between land and people in the developed regions with high pressure of protecting arable land by optimally using low-slope hilly land [14]. Compared to the plain areas, low-slope hilly land has the lower ecological carrying capacity and higher 
ecological sensitivity. Lack of good understanding of lowslope hilly land and objective evaluation of development activities will bring enormous environmental disturbance and destruction, resulting in serious or even irreversible consequences on the structure and function of ecosystems, biodiversity, and landscape in this area $[15,16]$. Therefore, it is of great significance to do the suitability assessment in low-slope hilly land and classify development levels in order to ensure the orderly development of it [17-19]. Since a framework for land evaluation reported by the Food and Agriculture Organization (FAO), the research of land use suitability assessment receives more and more attention. The theory, method, and specific scheme on land use suitability evaluation are also improved constantly. Currently, scholars usually carry out land suitability assessment in different regions [16, 20-22]. However, the screening of evaluation factor and the determination method of factor weight are both significant on the influence of the cultivated land suitability assessment. On the one hand, the evaluation factor is different in different areas such as the plateau region, hilly area, and flood plain area, and the emphasis of the research is different. Accordingly, on the other hand, the calculation method of factor weight can be divided into two categories $[12,23,24]$ : one is the mathematical logical reasoning based on knowledge and rules, containing the comprehensive index method and Fuzzy-AHP methods; this kind of methodology has higher dependency on knowledge and then makes the result more subjective. The other one is the data driven mechanism based on adaptive system such as neural network method. But its reasoning process is cumbersome and its algorithm is complex, which cannot effectively use existing knowledge and often leads to the fact that it is hard to explain the acquired rules. In view of the special natural and social economic conditions in Yunnan region, this paper determines the factor weights by the fuzzy weight of evidence model to avoid subjective influence, multiple collinear interference, and complex model algorithm. The paper provides a scientific basis for urbanization and optimal allocation of land through evaluating the development suitability levels of low-slope hilly resources (not including the ecological preservation areas) such as unused land, woodland, and grassland.

\section{Study Area}

Yunnan province $\left(97^{\circ} 31^{\prime} \sim 106^{\circ} 11^{\prime} \mathrm{W}, 21^{\circ} 8^{\prime} \sim 29^{\circ} 15^{\prime} \mathrm{N}\right)$ is a lowlatitude inland, spreading about 394,000 square kilometers which accounts for 4.11 percent of total area in China (Figure 1). It comprises mainly mountains, plateaus, hills, and small basins. Mountains and plateaus occupy around $94 \%$ of the province. Much of the province lies within the subtropical highland. There is little variance in annual temperature but a large diurnal temperature range. It has distinct wet and dry seasons. The temperature changes greatly with the terrain. Due to the interaction of climate, biology, geology, topography, and so on, various types of soil are formed. It is characterized by the vertical distribution of soil. The area of red soil accounts for $50 \%$ of the province.
Rainfall is unevenly distributed in terms of seasons and regions [25]. Yunnan province, with strong intensity in urban land use, is one of the provinces where mountain towns are widespread in China. Therefore, it is an inevitable choice for urbanization development to moderately develop the lowslope hilly regions in Yunnan province.

\section{Materials and Methods}

3.1. Data Acquisition. The main data in this study includes meteorological data mainly referring to daily average temperature in 2010 and rainfall in Yunnan province. These data were derived from the daily observation data of meteorological stations maintained by the China Meteorological Administration. Current land use data with the scale 1:100,000 in 2010 of Yunnan province (http://www.resdc.cn) is also used, which contains data regarding all land use types such as built-up land, woodland, grassland, and unused land. Terrain data with the scale $1: 25,000$ in Yunnan province is from Data Sharing Infrastructure of Earth System Science in China (http://www.geodata.cn/Portal/metadata/ viewMetadata.jsp?id=100101-11221). The outcome of overall land use plan (2006-2020) in Yunnan province which derived from the Office of Land and Resources in Yunnan province is used by the research.

ArcGIS10.0 is used to process Kriging interpolation on the rainfall distribution and average temperature distributions with meteorological data, which results in creating an annual rainfall distribution map and an annual temperature distribution map. Topographic data are used to generate digital elevation model (DEM) (whose spatial resolution is $1 \mathrm{~km} \times$ $1 \mathrm{~km}$ ) and a slope map. Buffer zones of water sources and state roads are obtained later. Therefore, based on the optimum distance, a map of distance to water and a map of distance to state roads are obtained, respectively. Interpolation analysis is done through socio-economic data, which generates a map of GDP per capita and a population distribution map in Yunnan in the grid with cells of $1 \times 1$ square kilometers [26-28]. The proportion of plain areas is obtained through land use data in Yunnan province [29]. With the help of geoscience data analysis system, the existing built-up land parcels in Yunnan are extracted as training samples suitable for construction and are used to make a distribution map of the sample. It should be noted that GeoDAS4.2 was developed by the Geomatics Research Group at York University, and it is a GIS software that synthesizes the fuzzy weight of evidence model, fractal model, spatial statistics, artificial intelligence, and other modern data processing techniques (http://www.yorku.ca/yul/gazette/past/archive/2002/ 030602/current.htm). A sampling interval of $1 \mathrm{~km} \times 1 \mathrm{~km}$ pixels is determined as the unit of area according to the minimum shape and size of the parcel of evaluation objects. Each map layer is saved in the form of GRID.

3.2. Research Methods. Fuzzy weight of evidence is evolved from weight of evidence which is firstly used in medical diagnosis without considering the space. Since 1980s, Agterberg et al. $[30,31]$ had modified this method and applied it 


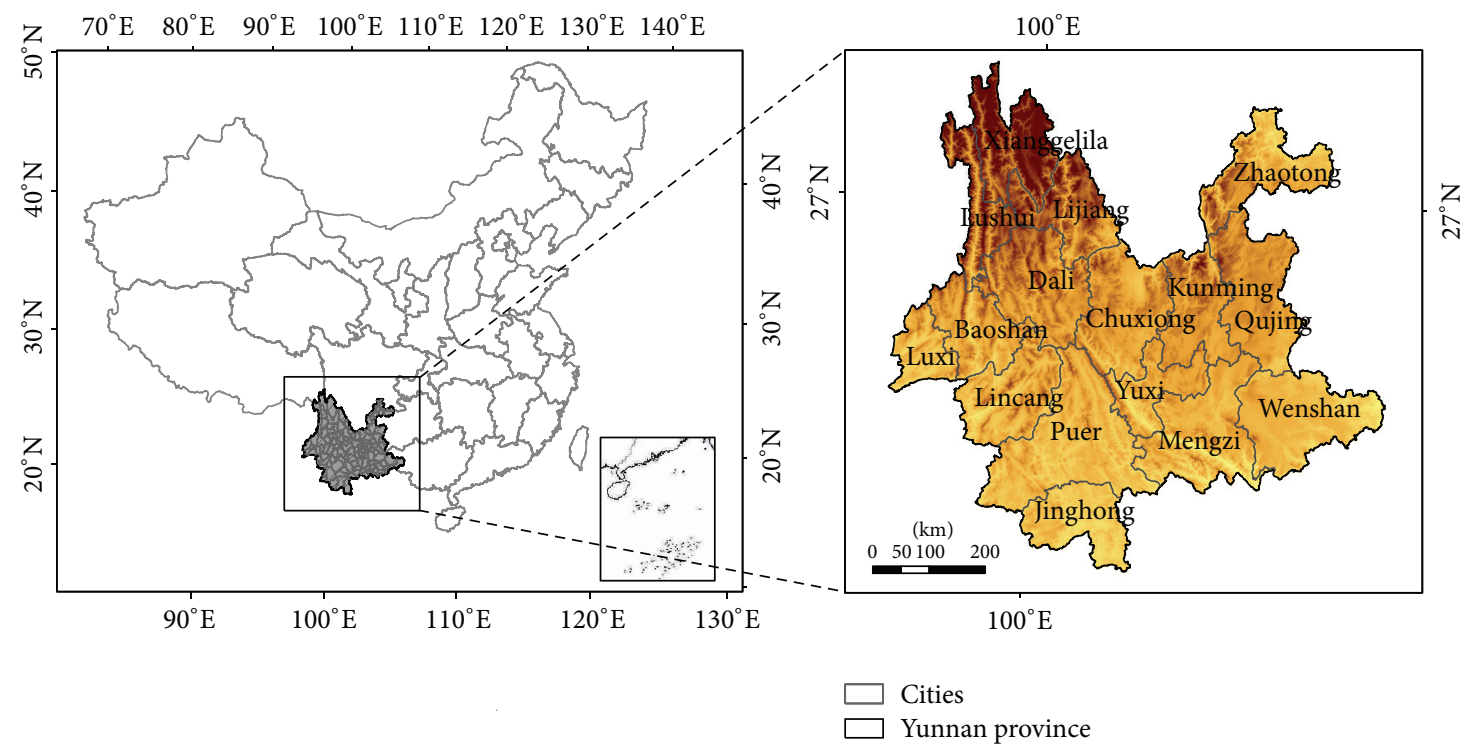

FIGURE 1: Location and DEM of Yunnan province.

on mineral forecast. Since this method can be applicable to integrate multiple information and spatial decision support systems, it has been applied in the evaluation on various mineral resources, geological disaster risk assessment, and environmental evaluation in recent years.

3.2.1. The Principle of the Method. Weight of evidence method is a log-linear model under a Bayesian probability criterion. A priori probabilities are firstly calculated. Then conditional probabilities are calculated under a certain geological evidence model. Weight of evidence method includes posterior logit model, the general weight of evidence model, fuzzy weight of evidence model, and weighted weight of evidence model. The principle of the method is as follows [32-34].

(1) Calculate A Priori Probabilities. Suppose total area of the study area $T$ is $A(T)$ which is divided into cells of a fixed area $u$. $D$ is the event to be predicted. It follows that there are $N(T)=A(T) / u$ cells totally in the study area where $A()$ represents the area and $N()$ is the number of cells. Therefore, the frequency of events $D$ in the study area $T$ is $N(D)$. The probability of the event is

$$
P(D)=\frac{N(D)}{T(D)}
$$

where $P(D)$ is the a priori probability, and the occurrence can be expressed as $O(D)=P(D) /(1-P(D))$.

(2) Calculate Weight of Evidence. Any weight of evidence (the map layer) $x$ is binary. Its weight is defined as

$$
W^{+}=\ln \left[\frac{P(B / D)}{P(B / \bar{D})}\right] \text {, }
$$

$$
W^{-}=\ln \left[\frac{P(\bar{B} / D)}{P(\bar{B} / \bar{D})}\right]
$$

where $W^{+}$and $W^{-}$represent the weight for presence of $B$ and weight for absence of $\bar{B}$, respectively. $P(B / D)=$ $N(B \cap D) / N(D)$ denotes the probability of selected weight of evidence $D$ in any unit cell of $B$, where $N(B \cap D)$ stands for the occurrence of weight in $B$ and $N(D)$ is the total number of occurrence in the study area. Other equations can be explained in the same way.

(3) Calculate Posterior Probability. If there is $n$ number of weights which are independent of each other on the occurrence, the probability of the occurrence of any cell in the study area can be expressed by the posterior probability logarithm which is expressed as follows:

$$
\ln O\left(D \mid B_{1}^{k} \cap B_{2}^{k} \cap B_{3}^{k} \cdots B_{n}^{k}\right)=\sum_{m=1}^{n} W_{m}^{k}+\ln O(D),
$$

where $m=(1,2,3, \ldots n)$, and $k$ indicates the presence and absence of the weight, namely,

$$
W_{m}^{k}=\left\{\begin{array}{l}
W_{m}^{+} \\
W_{m}^{-} \\
0,
\end{array}\right.
$$

where $W_{m}^{+}$is the weight for presence of weight $m . W_{m}^{-}$is the weight for absence of weight $m .0$ is the weight for missing of weight $m$. Accordingly, the posterior probability can be expressed as

$$
P=\frac{O}{(1+O)}
$$




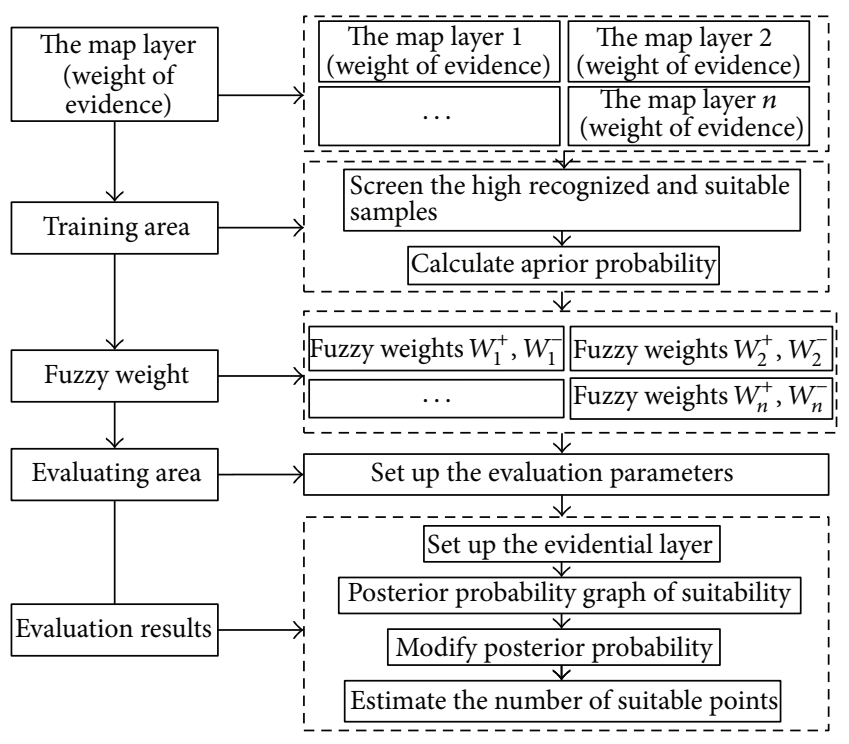

FIGURE 2: Flowchart of fuzzy weight of evidence.

(4) Membership Function. Weight of evidence approach will result in loss of data while doing binary process for map layers which will affect the accuracy of assessment. Cheng and Agterberg [35] have developed a fuzzy weight of evidence approach which automatically copes with the missing data on discrete layers. Fuzzy weight of evidence uses ambiguity membership of layers which is determined by membership function to deal with multiclassification layers. Multivalued fuzzy membership function $0 \leq u(x) \leq 1$ is used to fit training samples. The weight of evidence is calculated in the end.

3.2.2. Procedures. The procedures of fuzzy weight of evidence (Figure 2) are as follows. (1) Identify research objectives, such as suitability of the development of the low-slope hilly regions; select the samples and calculate the a priori probabilities. (2) Determine the spatial layer related to the target; screen indicators; and establish an index system. (3) Extract map layers related to the target; use fuzzy membership functions to represent the credibility of the map layer. (4) Calculate the weight of fuzzy map layer; determine the value of the map layer; and screen indicators. (5) Integrate multiple fuzzy map layers and calculate a priori probabilities in order to obtain a suitability map in low-slope hilly regions. (6) Modify posterior probabilities; test the model; and make an interpretation for suitability distribution.

\section{Results and Analysis}

4.1. Training Samples and A Priori Probabilities. That selected training samples should follow two principles. (1) The training samples should be the given information approved by the public and the relevant departments. (2) The training samples should distribute widely in the research area. According to current land use data in Yunnan province, the existing builtup land parcels in Yunnan province are taken as samples

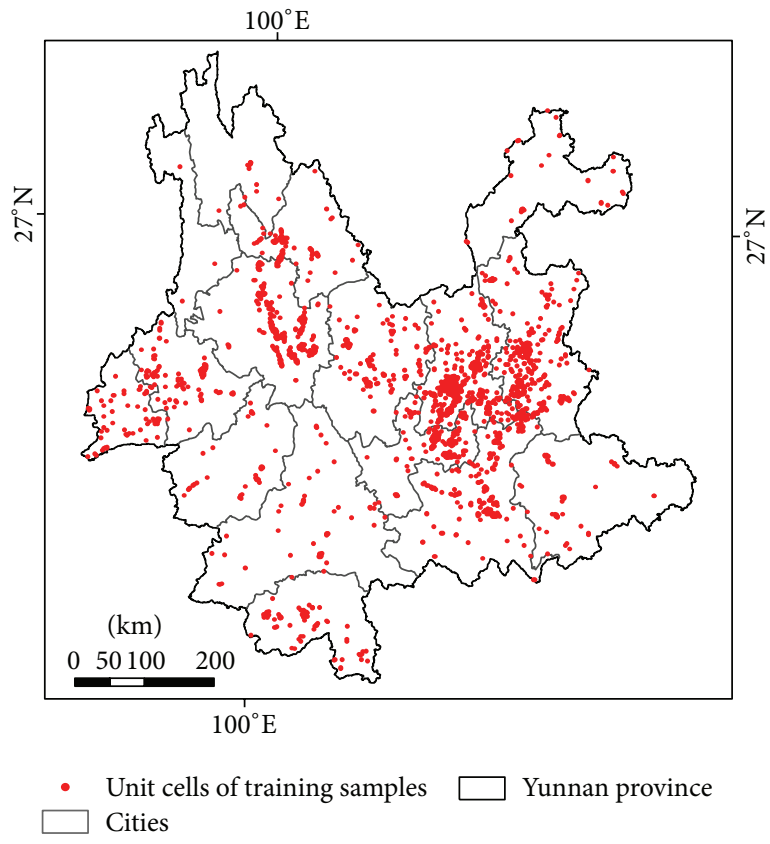

FIGURE 3: Distribution of training samples.

suitable for urban development. The priori probability can be known by integrating (1) that the total number of unit cells of training samples is 2332 (Figure 3).There are 220,084 unit cells in the whole areas. The priori probability is 0.010596 .

4.2. Fuzzy Map Layers and Weight of Evidence. The selection of evaluation factors is under the principle of dissimilarity, stability, and reality. On the basis of previous research on land use suitability assessment in low-slope hilly regions and built-up land, the evaluation index system of land use suitability assessment in low-slope hilly regions mainly refers to climate, topography, geography, and socioeconomic conditions. Impact factors include temperature, rainfall, elevation, slope, proportion of plain area, distance to water, distance to state roads, population distribution, and GDP per capita (Figure 4).

Each fuzzy weight of evidence is calculated by GeoDAS4.2. The influence of individual factors on the incident can be known which leads to the objective decision on choosing evaluation factors. Final map layers and parameters of fuzzy weights of evidence can be seen in Table 1 through (2) and multivalued fuzzy membership function.

4.3. The Posterior Probability and Its Modification. These map layers are synthesized and the posterior probability map in Yunnan is calculated by (5). Then the posterior probability map of land use suitability in low-slope hilly regions in Yunnan is made by taking reserved land parcels in low-slope hilly regions as the crop box (Figure 5). Posterior probabilities are affected by the setting of the unit cell. However, they do not affect the distribution of posterior probabilities. Therefore, posterior probabilities do not represent the probability of occurrences but the distribution after occurrences. 

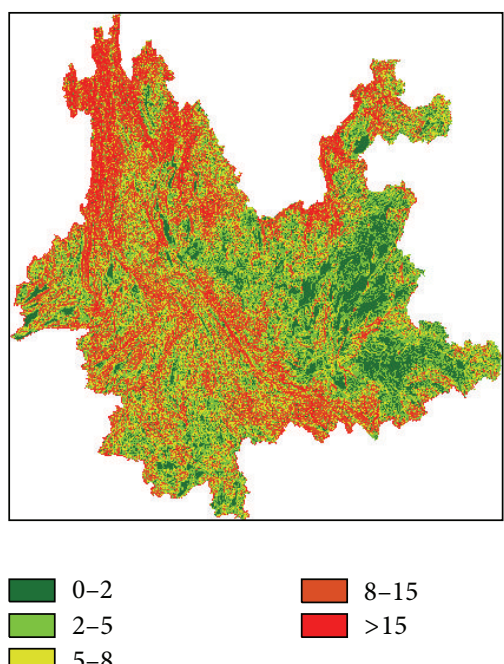

(a)
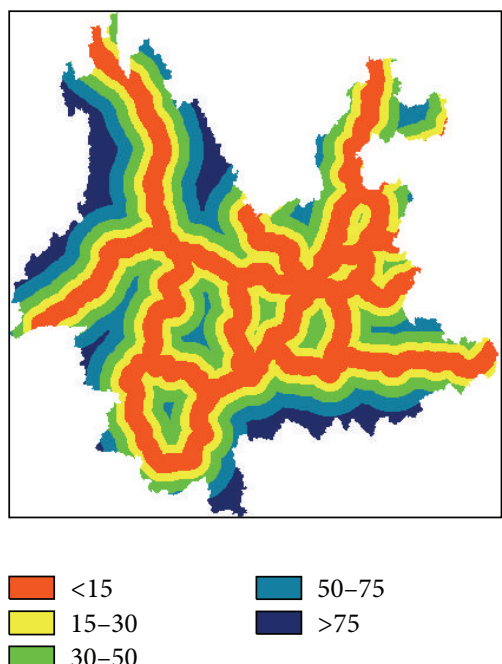

(d)
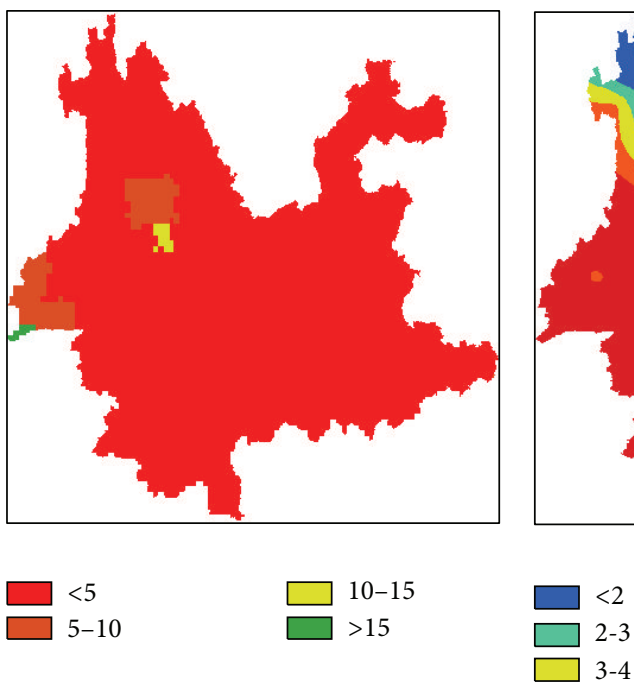

(g)

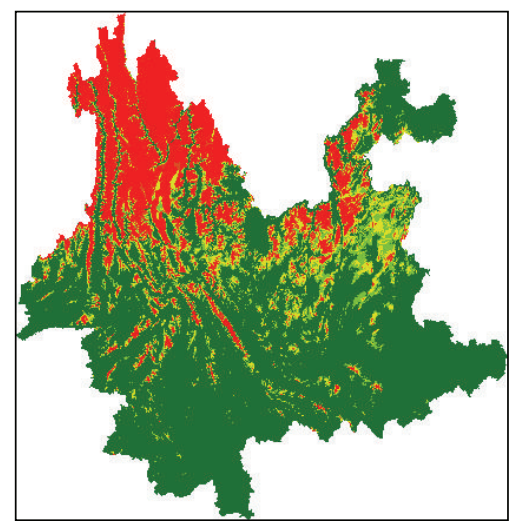

$\square<1500$
$\square \quad 1500-1750$

$\square$ 2000-2250

$>2250$

(b)

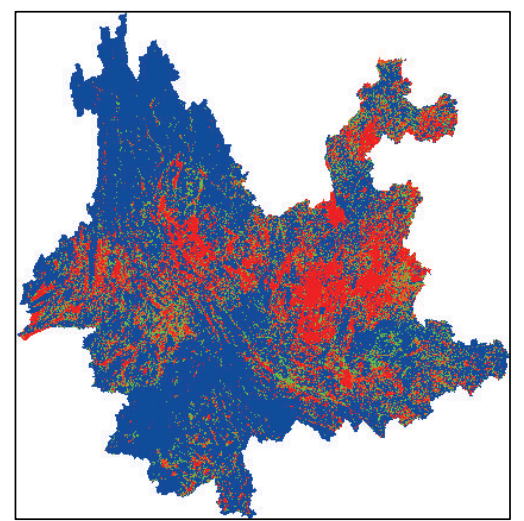

$<5000$

5000-10000

$\square$ 10000-20000

$>20000$

(e)
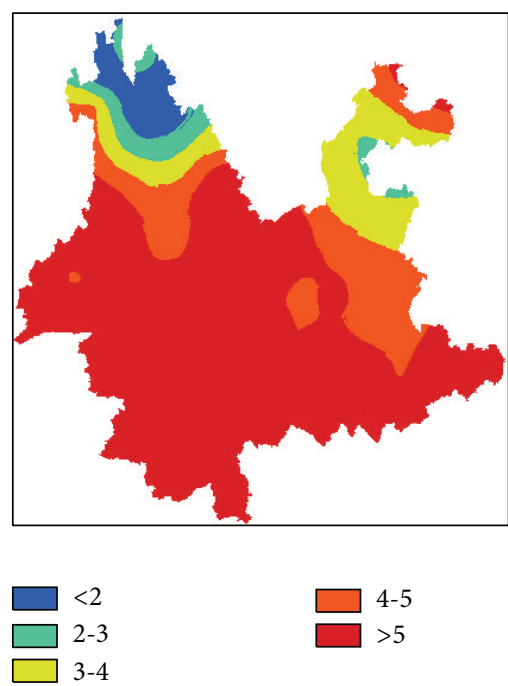

(h)
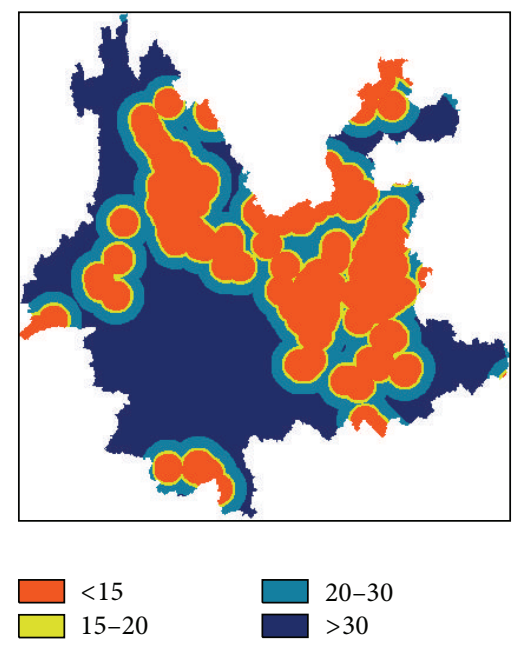

(c)
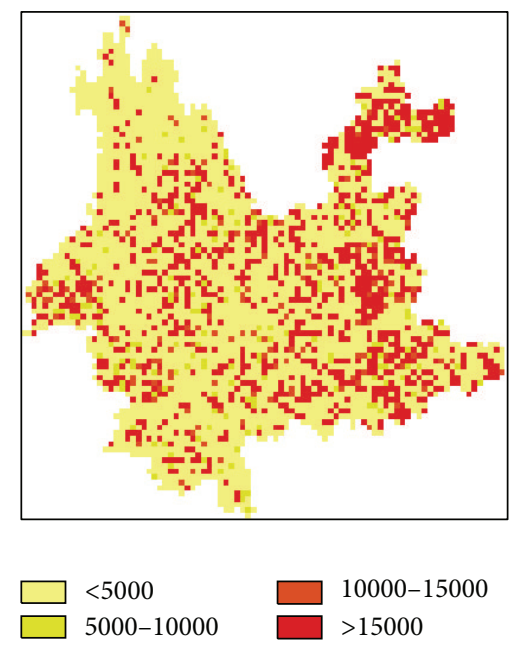

(f)
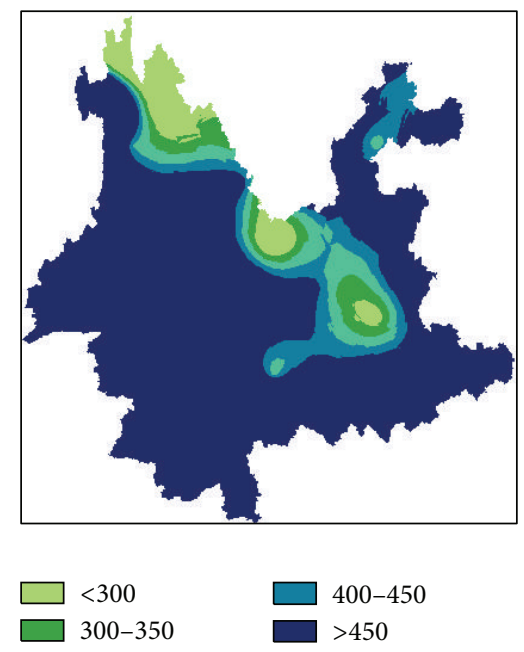

350-

(i)

Figure 4: Nine-factor maps. (a) Slope $\left(^{\circ}\right)$; (b) elevation (m); (c) distance to water (Km); (d) distance to state roads (Km); (e) GDP per capita (Yuan); (f) population (person); (g) proportion of plain areas (\%); (h) annual average temperature $\left({ }^{\circ} \mathrm{C}\right)$; (i) annual rainfall (mm). 
TABle 1: Parameters of fuzzy weights of evidence for each map layer.

\begin{tabular}{|c|c|c|c|c|c|c|c|c|c|c|}
\hline & Classification value & $W^{+}$ & $W^{-}$ & $C$ & STDEV & $T$ & MSF & FW & $S(\mathrm{FW})$ & $T(\mathrm{FW})$ \\
\hline \multirow{5}{*}{ Slope $/\left({ }^{\circ}\right)$} & $0 \sim 2$ & 1.38 & -0.69 & 2.07 & 0.04 & 49.10 & 1.00 & 1.38 & 0.03 & 49.62 \\
\hline & $2 \sim 5$ & 0.68 & -1.21 & 1.89 & 0.05 & 34.35 & 0.60 & 1.03 & 0.08 & 13.50 \\
\hline & $5 \sim 8$ & 0.36 & -1.44 & 1.79 & 0.07 & 24.30 & 0.38 & 0.68 & 0.12 & 5.91 \\
\hline & $8 \sim 15$ & 0.09 & -2.03 & 2.12 & 0.19 & 11.32 & 0.15 & -0.06 & 0.16 & -0.37 \\
\hline & $>15$ & & & & & & 0.00 & -2.03 & 0.19 & -10.92 \\
\hline \multirow{5}{*}{ Elevation (m) } & $<1500$ & 0.28 & -0.82 & 1.10 & 0.06 & 19.37 & 1.00 & 0.28 & 0.02 & 12.18 \\
\hline & $1500 \sim 1750$ & 0.24 & -1.15 & 1.38 & 0.07 & 18.99 & 0.80 & 0.22 & 0.03 & 6.28 \\
\hline & 1750 2000 & 0.20 & -1.69 & 1.89 & 0.11 & 17.52 & 0.68 & 0.17 & 0.05 & 3.40 \\
\hline & $2000 \sim 2250$ & 0.17 & -2.16 & 2.32 & 0.15 & 15.59 & 0.40 & -0.03 & 0.09 & -0.29 \\
\hline & $>2250$ & & & & & & 0.00 & -2.16 & 0.15 & -14.62 \\
\hline \multirow{4}{*}{ Distance to water $/ \mathrm{km}$} & $<15$ & 0.83 & -1.17 & 2.00 & 0.05 & 38.85 & 1.0 & 0.83 & 0.02 & 35.72 \\
\hline & $15 \sim 20$ & 0.71 & -1.26 & 1.97 & 0.06 & 35.39 & 0.8 & 0.61 & 0.02 & 26.25 \\
\hline & $20 \sim 30$ & 0.41 & -1.49 & 1.90 & 0.07 & 26.06 & 0.4 & -0.01 & 0.04 & -0.19 \\
\hline & $>30$ & & & & & & 0.0 & -1.49 & 0.07 & -21.43 \\
\hline \multirow{5}{*}{ Distance to state roads $/ \mathrm{km}$} & $<15$ & 0.72 & -0.79 & 1.51 & 0.05 & 33.35 & 1.00 & 0.72 & 0.02 & 29.02 \\
\hline & $15 \sim 30$ & 0.42 & -1.20 & 1.62 & 0.06 & 26.05 & 0.68 & 0.63 & 0.06 & 11.12 \\
\hline & $30 \sim 50$ & 0.18 & -1.31 & 1.49 & 0.09 & 16.66 & 0.40 & 0.46 & 0.10 & 4.51 \\
\hline & $50 \sim 75$ & 0.07 & -1.64 & 1.71 & 0.17 & 10.02 & 0.20 & 0.16 & 0.14 & 1.15 \\
\hline & $>75$ & & & & & & 0.00 & -1.64 & 0.17 & -9.71 \\
\hline \multirow{4}{*}{ GDP per capita/Yuan } & $<5000$ & & & & & & 0.00 & -2.24 & 0.08 & -28.60 \\
\hline & $5000 \sim 10000$ & 1.00 & -2.24 & 3.24 & 0.08 & 39.85 & 0.40 & -0.19 & 0.05 & -3.92 \\
\hline & $10000 \sim 20000$ & 1.31 & -1.97 & 3.28 & 0.07 & 48.71 & 0.85 & 1.10 & 0.02 & 48.67 \\
\hline & $>20000$ & 1.60 & -1.74 & 3.34 & 0.06 & 56.64 & 1.00 & 1.60 & 0.02 & 70.40 \\
\hline \multirow{4}{*}{ Population/person } & $<5000$ & 0.01 & -0.77 & 0.78 & 0.22 & 3.55 & 0.0 & -0.38 & 0.03 & -12.26 \\
\hline & $5000 \sim 10000$ & 0.52 & -0.39 & 0.91 & 0.04 & 21.71 & 0.6 & 0.11 & 0.02 & 5.18 \\
\hline & $10000 \sim 15000$ & 0.58 & -0.36 & 0.94 & 0.04 & 22.62 & 0.8 & 0.35 & 0.03 & 13.78 \\
\hline & $>15000$ & 0.65 & -0.34 & 0.99 & 0.04 & 23.84 & 1.0 & 0.65 & 0.03 & 21.21 \\
\hline \multirow{4}{*}{ Proportion of plain areas/\% } & $<5$ & 0.00 & -1.38 & 1.38 & 0.58 & 2.38 & 0.0 & -0.04 & 0.02 & -1.74 \\
\hline & $5 \sim 10$ & 0.59 & -0.04 & 0.64 & 0.07 & 8.60 & 0.4 & -0.02 & 0.05 & -0.39 \\
\hline & $10 \sim 15$ & 1.77 & -0.03 & 1.80 & 0.12 & 14.74 & 1.0 & 1.77 & 0.12 & 14.75 \\
\hline & $>15$ & 0.80 & 0.00 & 0.81 & 0.34 & 2.40 & 1.0 & 1.77 & 0.12 & 14.75 \\
\hline \multirow{5}{*}{ Annual average temperature $/{ }^{\circ} \mathrm{C}$} & $<2$ & & & & & & 0.00 & -2.16 & 0.30 & -7.18 \\
\hline & $2 \sim 3$ & 0.04 & -2.17 & 2.20 & 0.30 & 7.28 & 0.65 & 0.05 & 0.11 & 0.46 \\
\hline & $3 \sim 4$ & 0.07 & -1.85 & 1.92 & 0.19 & 10.29 & 1.00 & 0.07 & 0.02 & 3.36 \\
\hline & $4 \sim 5$ & 0.12 & -0.86 & 0.98 & 0.08 & 12.55 & 1.00 & 0.07 & 0.02 & 3.36 \\
\hline & $>5$ & -0.33 & 0.44 & -0.77 & 0.04 & -18.62 & 1.00 & 0.07 & 0.02 & 3.36 \\
\hline \multirow{5}{*}{ Annual rainfall/mm } & $<300$ & & & & & & 0.0 & -1.40 & 0.27 & -5.25 \\
\hline & $300 \sim 350$ & & & & & & 0.0 & -1.40 & 0.27 & -5.25 \\
\hline & $350 \sim 400$ & 0.02 & -1.40 & 1.42 & 0.27 & 5.31 & 0.3 & -0.09 & 0.19 & -0.50 \\
\hline & $400 \sim 450$ & 0.02 & -0.47 & 0.49 & 0.11 & 4.39 & 0.8 & -0.05 & 0.06 & -0.91 \\
\hline & $>500$ & -0.05 & 0.23 & -0.27 & 0.05 & -5.16 & 1.0 & -0.05 & 0.02 & -2.00 \\
\hline
\end{tabular}

$W^{+}$: positive weight; $W^{-}$: negative weight; $C$ : contrast of $W^{+}-W^{-}$; STDEV: standard deviation of $C$; $T$ : significance level; MSF: membership; FW: fuzzy weight; $S(\mathrm{FW})$ : standard deviation of fuzzy weight; T(FW): significance of fuzzy weight. Among them, GDP is the present value of 2010.

The map layer of fuzzy weight of evidence model is required to meet the needs of conditional independence. However, in reality, it is very difficult to achieve this which inevitably results in the deviation of posterior probabilities. The modified posterior probability can overcome the deficit of less accurate estimation on appropriate points.
Data tests of the linear function correction, logarithmic function correction, and exponential function correction are carried out with the help of GeoDAS4.2's posterior probability correction module. Ultimately, exponential function model $Y=0.12 x^{0.96}$ with optimal fitting degree is determined. After the modification of the posterior probability, the 


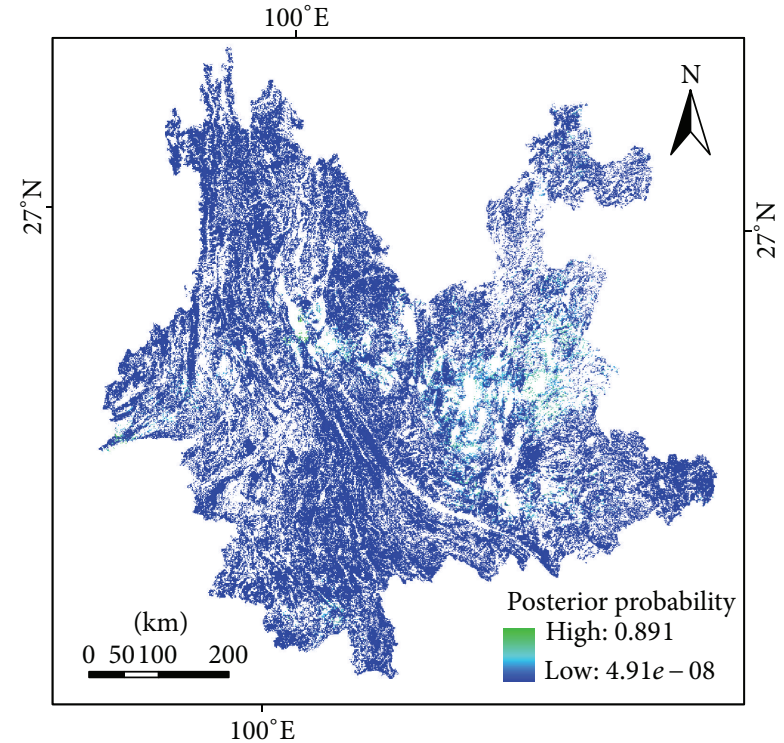

FIGURE 5: Posterior probability map of land use suitability.

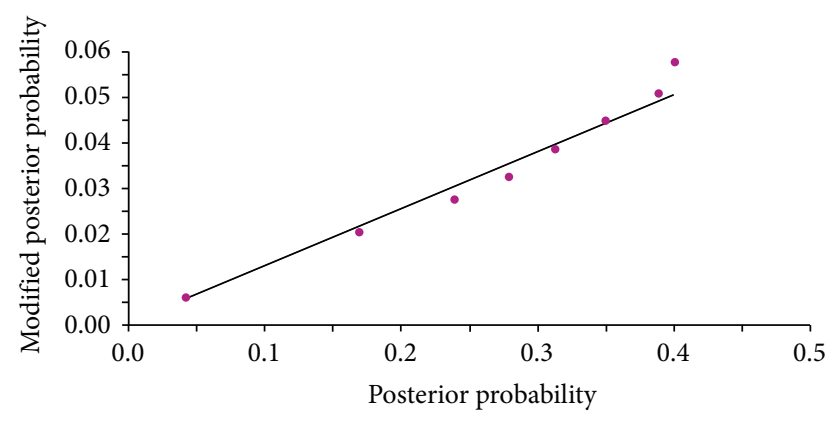

FIgURE 6: Modification on posterior probabilities.

coefficient of determination $R$ is equal to 0.98 . Procedures and results of the modification are shown in Figures 6 and 7.

4.4. Classification of Land Use Suitability in Low-Slope Hilly Regions. The posterior probability map is modified according to an exponential function model, which is used to create the modified posterior probability map. On the basis of this, the distribution frequency of modified posterior probabilities is analyzed. Distribution frequency curve is used. Finally, land use suitability in low-slope hilly regions in Yunnan province is divided into four levels (Table 2, Figure 8) according to obvious inflection point of the frequency curve and parameters of the weight of evidence of those evaluation factors.

There are four levels in terms of land use suitability in low-slope hilly regions in the study area: highly suitable, moderately suitable, marginally suitable, and unsuitable. (1) $9.33 \%$ of the land is highly suitable for development, mostly distributed in Kunming, Lijiang, Dali Bai autonomous prefecture, Qujing, and so on. Spatially, highly suitable areas are mainly located around cities where its terrain is relatively

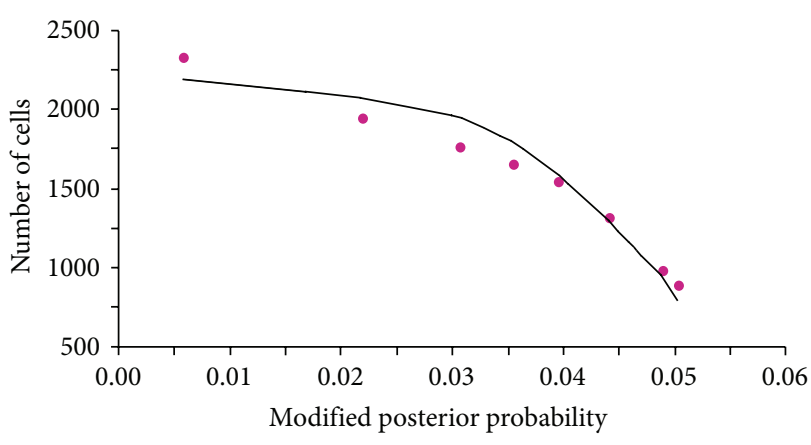

FIGURE 7: Modified posterior probabilities of land use suitability and numbers of corresponding points.

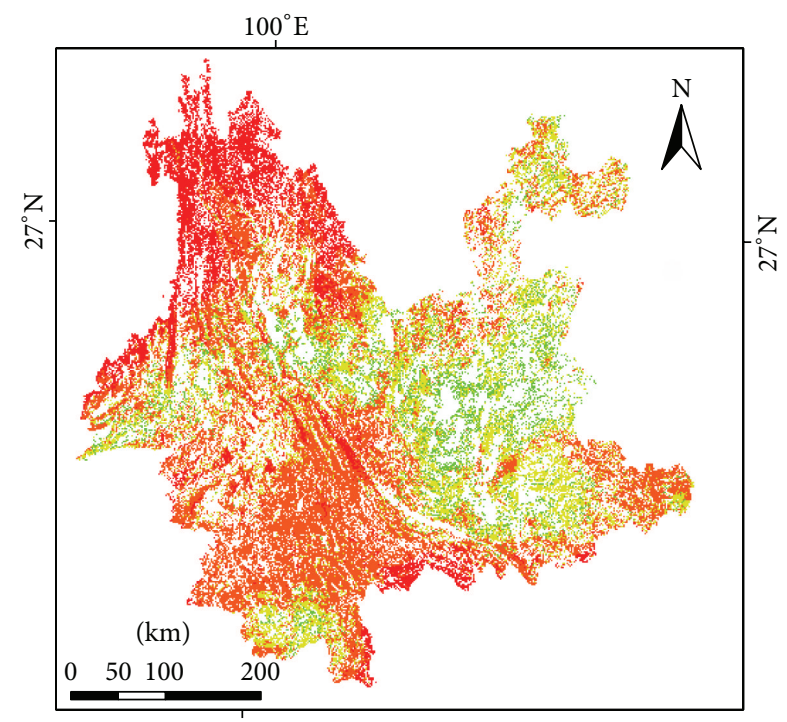

$100^{\circ} \mathrm{E}$

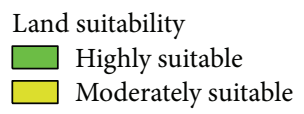

Marginally suitable Unsuitable

FIGURE 8: Classification map of land use suitability in low-slope hilly regions in Yunnan.

flat with slopes below 5 degrees and altitude mostly below $1500 \mathrm{~m}$. The plain area accounts for more than $15 \%$ of the total area. Usually, the distance to water and state roads is no more than $15 \mathrm{~km}$. GDP per capita is higher than 20,000 yuan. It is densely populated with 1,500 people $/ \mathrm{km}^{2}$. Its average annual temperatures are relatively high with abundant rainfall. (2) $26.18 \%$ of land is moderately suitable where it still has good natural resource and socioeconomic conditions with slopes ranging from 5 degrees to 8 degrees. It is close to towns. GDP per capita ranging from about 10,000 to 20,000 yuan is high. The population is relatively concentrated in these areas with a population density of 10,000 to 15,000 people $/ \mathrm{km}^{2}$. It has adequate rainfall and pleasant weather suitable for living. (3) $45.98 \%$ of land is marginally suitable for development. It is widely spread. Compared with highly suitable and moderately suitable areas, basic conditions in this area are relatively poor. However, it has strong potential for transformation, 
TABLE 2: Classification of land use suitability in low-slope hilly regions in Yunnan.

\begin{tabular}{lcccc}
\hline Modified posterior probability & Suitability level & Numbers of cells & Description & Percentage of area/\% \\
\hline$>0.01047 \sim 0.10860$ & Level 1 & 20315 & Highly suitable & 9.33 \\
$>0.00050 \sim 0.10467$ & Level 2 & 56997 & Moderately suitable & 26.18 \\
$>0.00002 \sim 0.00050$ & Level 3 & 100131 & Marginally suitable & 45.98 \\
$<0.00002$ & Level 4 & 40309 & Unsuitable & 18.51 \\
\hline
\end{tabular}

which can be the main source of future development for some time. Therefore, its development potential, the overall size, and spatial layout should be the focus of policy makers. (4) $18.51 \%$ of land is unsuitable for development. These areas are more dispersed with slopes above 15 degrees in general and altitude mostly above $2200 \mathrm{~m}$. The proportion of plain area is less than $5 \%$ of the total area. It is far away from water resources and state roads. GDP per capita is low and population density is relatively small. It is far away from cities and towns. It is not suitable for living due to the relatively unpleasant weather. At the same time, it is prone to geological disasters and ecological risks, inappropriate for development and construction. In summary, the four levels of the suitability assessment in low-slope hilly regions in Yunnan province can provide a basis for the priority of development in these regions. Under the consideration of social-economic development, urbanization, and ecological safety, the paper offers strategies to develop low-slope hilly regions, which focus on the exploration of unused land and give preferential protection to woodland and grassland. In addition, comparing the results of this paper with the achievement of the outcome of overall land use plan, it can be known that, as far as quantity structure is concerned, it is quite scientific and reasonable that the area of highly suitable resources of low-slope hilly regions is much larger than the built-up land index of the planning phase (2006-2020); as for the spatial distribution, the layout of the built-up land in the planning phase is basically consistent with the highly suitable low-slope hilly regions or is distributed in its perimeter zone.

\section{Conclusion and Discussion}

Due to global climate change and urbanization in China, the conflict between land development and land conservation has become increasingly serious [36]. The development of lowslope hilly regions is an important measure to alleviate the conflict. This paper takes Yunnan province as a typical case study, integrating natural geographical features and elements of human geography in Yunnan province to analyze land use suitability of low-slope hilly regions in Yunnan province and avoid potential geological disasters and ecological risks in those regions. Land use suitability of low-slope hilly regions in Yunnan province is evaluated by analyzing some factors referring to climate, topography, geography, society, and economy. Nine map layers regarding temperature, rainfall, elevation, slope, proportion of plain areas, distance to water, distance to state roads, population distribution, and GDP per capita are selected. The results show that (1) 9.33\% of lowslope hilly regions in Yunnan are highly suitable for development. $26.18 \%$ of land is moderately suitable. $45.98 \%$ of land is generally suitable. The remaining $18.51 \%$ of land is unsuitable for development. This outcome of spatial distribution of lowslope hilly land in Yunnan province can finally optimize the size and layout of low-slope hilly land and promote the rational use of it. However, it is worth mentioning that not only the suitability of natural quality should be considered, but also some factors such as social and economic suitability, ecological suitability, and land policy should be taken into consideration. The related research will provide references for the plan of "town of mountain" in Yunnan and for the development of low-slope hilly land in Yunnan province. As for the model used in this study, it should be pointed out that training samples chosen in the study must be highly recognized appropriate points to ensure scientific results. Therefore, future research should pay more attention to how to ensure diversification of the given sources and improve the accuracy of given information.

\section{Conflict of Interests}

The authors declare no conflict of interests.

\section{Acknowledgments}

This research was financially supported by the major research plan of the National Natural Science Foundation of China (Grant no. 91325302), the National Natural Science Funds of China for Distinguished Young Scholar (Grant no. 71225005), and National Key Programme for Developing Basic Science in China (Grant no. 2010CB950900).

\section{References}

[1] R. Lal, "Soil carbon sequestration impacts on global climate change and food security," Science, vol. 304, no. 5677, pp. 16231627, 2004.

[2] G. C. S. Lin and S. P. S. Ho, "China's land resources and land-use change: insights from the 1996 land survey," Land Use Policy, vol. 20, no. 2, pp. 87-107, 2003.

[3] Y. Xie, Y. Mei, T. Guangjin, and X. Xuerong, "Socio-economic driving forces of arable land conversion: a case study of Wuxian City, China," Global Environmental Change, vol. 15, no. 3, pp. 238-252, 2005.

[4] P. Hao, S. Geertman, P. Hooimeijer, and R. Sliuzas, "The landuse diversity in urban villages in Shenzhen," Environment and Planning A, vol. 44, no. 11, pp. 2742-2764, 2012.

[5] L. Jiang, X. Deng, and K. C. Seto, "Multi-level modeling of urban expansion and cultivated land conversion for urban hotspot counties in China," Landscape and Urban Planning, vol. 108, no. 2-4, pp. 131-139, 2012. 
[6] L. Jiang, X. Deng, and K. C. Seto, "The impact of urban expansion on agricultural land use intensity in China," Land Use Policy, vol. 35, pp. 33-39, 2013.

[7] E. Keys and W. J. McConnell, "Global change and the intensification of agriculture in the tropics," Global Environmental Change, vol. 15, no. 4, pp. 320-337, 2005.

[8] I. Eng, "The rise of manufacturing towns: externally driven industrialization and urban development in the Pearl River Delta of China," International Journal of Urban and Regional Research, vol. 21, no. 4, pp. 554-568, 1997.

[9] Y. Liu and Y. Li, "Environment: China's land creation project stands firm," Nature, vol. 511, no. 7510, article 410, 2014.

[10] J. Liu, J. Zhan, and X. Deng, "Spatio-temporal patterns and driving forces of urban land expansion in China during the economic reform era," Ambio, vol. 34, no. 6, pp. 450-455, 2005.

[11] X. Deng, J. Huang, S. Rozelle, and E. Uchida, "Economic growth and the expansion of urban land in China," Urban Studies, vol. 47, no. 4, pp. 813-843, 2010.

[12] J. Gong, Y. Liu, and W. Chen, "Land suitability evaluation for development using a matter-element model: a case study in Zengcheng, Guangzhou, China," Land Use Policy, vol. 29, no. 2, pp. 464-472, 2012.

[13] J. S. Jeong, L. García-Moruno, and J. Hernández-Blanco, “A site planning approach for rural buildings into a landscape using a spatial multi-criteria decision analysis methodology," Land Use Policy, vol. 32, pp. 108-118, 2013.

[14] P. La Greca, D. La Rosa, F. Martinico, and R. Privitera, "Agricultural and green infrastructures: the role of non-urbanised areas for eco-sustainable planning in a metropolitan region," Environmental Pollution, vol. 159, no. 8-9, pp. 2193-2202, 2011.

[15] R. S. Sicat, E. J. M. Carranza, and U. B. Nidumolu, "Fuzzy modeling of farmers' knowledge for land suitability classification," Agricultural Systems, vol. 83, no. 1, pp. 49-75, 2005.

[16] T. V. Reshmidevi, T. I. Eldho, and R. Jana, "A GIS-integrated fuzzy rule-based inference system for land suitability evaluation in agricultural watersheds," Agricultural Systems, vol. 101, no. 12, pp. 101-109, 2009.

[17] J. Malczewski, "Ordered weighted averaging with fuzzy quantifiers: GIS-based multicriteria evaluation for land-use suitability analysis," International Journal of Applied Earth Observation and Geoinformation, vol. 8, no. 4, pp. 270-277, 2006.

[18] J. Marull, J. Pino, J. M. Mallarach, and M. J. Cordobilla, "A land suitability index for strategic environmental assessment in metropolitan areas," Landscape and Urban Planning, vol. 81, no. 3, pp. 200-212, 2007.

[19] R. J. Zomer, A. Trabucco, D. A. Bossio, and L. V. Verchot, "Climate change mitigation: a spatial analysis of global land suitability for clean development mechanism afforestation and reforestation," Agriculture, Ecosystems and Environment, vol. 126, no. 1-2, pp. 67-80, 2008.

[20] S. V. Bobade, B. P. Bhaskar, M. S. Gaikwad et al., "A GISbased land use suitability assessment in Seoni district, Madhya Pradesh, India," Tropical Ecology, vol. 51, no. 1, pp. 41-54, 2010.

[21] D. D'haeze, J. Deckers, D. Raes, T. A. Phong, and H. V. Loi, "Environmental and socio-economic impacts of institutional reforms on the agricultural sector of Vietnam: land suitability assessment for Robusta coffee in the Dak Gan region," Agriculture, Ecosystems \& Environment, vol. 105, no. 1-2, pp. 59-76, 2005.

[22] Y.-S. Liu, J.-Y. Wang, and L.-Y. Guo, "GIS-based assessment of land suitability for optimal allocation in the Qinling Mountains, China," Pedosphere, vol. 16, no. 5, pp. 579-586, 2006.
[23] Y. Chen, J. Yu, and S. Khan, "Spatial sensitivity analysis of multi-criteria weights in GIS-based land suitability evaluation," Environmental Modelling and Software, vol. 25, no. 12, pp. 15821591, 2010.

[24] O. Marinoni, "A discussion on the computational limitations of outranking methods for land-use suitability assessment," International Journal of Geographical Information Science, vol. 20, no. 1, pp. 69-87, 2006.

[25] C. Zhao, X. Deng, Y. Yuan, H. Yan, and H. Liang, "Prediction of drought risk based on the WRF model in Yunnan province of China," Advances in Meteorology, vol. 2013, Article ID 295856, 9 pages, 2013.

[26] X. Deng, H. Su, and J. Zhan, "Integration of multiple data sources to simulate the dynamics of land systems," Sensors, vol. 8, no. 2, pp. 620-634, 2008.

[27] X. Deng, J. Huang, Q. Huang, S. Rozelle, and J. Gibson, “Do roads lead to grassland degradation or restoration? A case study in Inner Mongolia, China," Environment and Development Economics, vol. 16, no. 6, pp. 751-773, 2011.

[28] X. Deng, J. Huang, E. Uchida, S. Rozelle, and J. Gibson, “Pressure cookers or pressure valves: do roads lead to deforestation in China?" Journal of Environmental Economics and Management, vol. 61, no. 1, pp. 79-94, 2011.

[29] X. Deng, J. Huang, S. Rozelle, and E. Uchida, "Growth, population and industrialization, and urban land expansion of China," Journal of Urban Economics, vol. 63, no. 1, pp. 96-115, 2008.

[30] F. P. Agterberg, "Computer programs for mineral exploration," Science, vol. 245, no. 4913, pp. 76-81, 1989.

[31] F. Agterberg, G. Bonham-Carter, Q. Cheng, and D. Wright, "Weights of evidence modeling and weighted logistic regression for mineral potential mapping," Computers in Geology, vol. 25, pp. 13-32, 1993.

[32] F. P. Agterberg and Q. Cheng, "Conditional independence test for weights-of-evidence modeling," Natural Resources Research, vol. 11, no. 4, pp. 249-255, 2002.

[33] F. Agterberg, "A modified weights-of-evidence method for regional mineral resource estimation," Natural Resources Research, vol. 20, no. 2, pp. 95-101, 2011.

[34] G. Jin, Z. Wang, X. Hu, S. Hu, and D. Zhang, "Land suitability evaluation in Qinghai-Tibet Plateau based on fuzzy weight of evidence model," Transactions of the Chinese Society of Agricultural Engineering, vol. 29, no. 18, pp. 241-250, 2013 (Chinese).

[35] Q. Cheng and F. P. Agterberg, "Fuzzy weights of evidence method and its application in mineral potential mapping," Natural Resources Research, vol. 8, no. 1, pp. 27-35, 1999.

[36] J. Luo, J. Zhan, Y. Lin, and C. Zhao, "An equilibrium analysis of the land use structure in the Yunnan Province, China," Frontiers of Earth Science, 2014. 

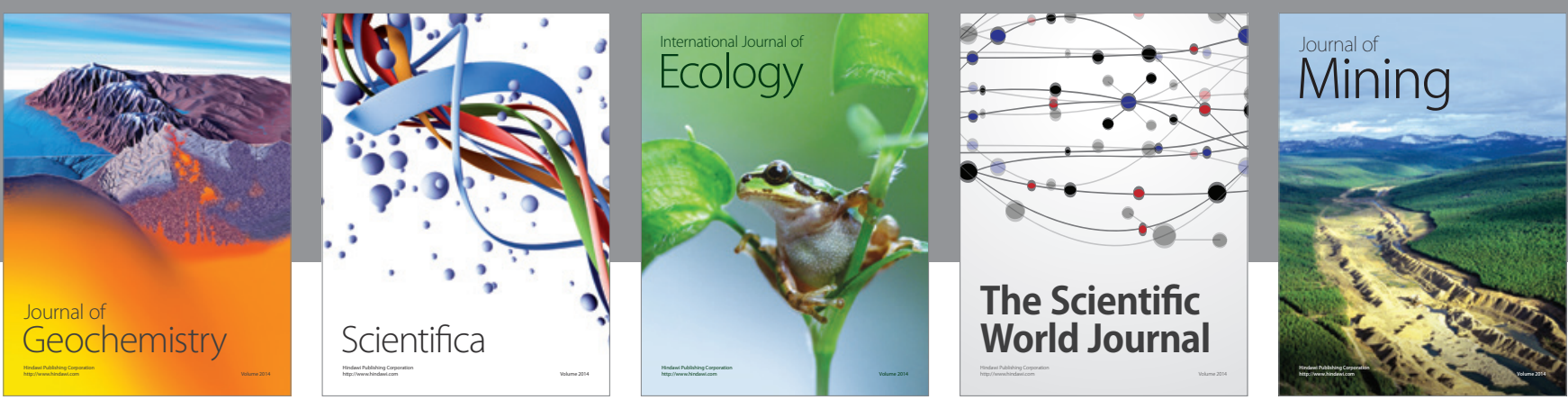

The Scientific World Journal
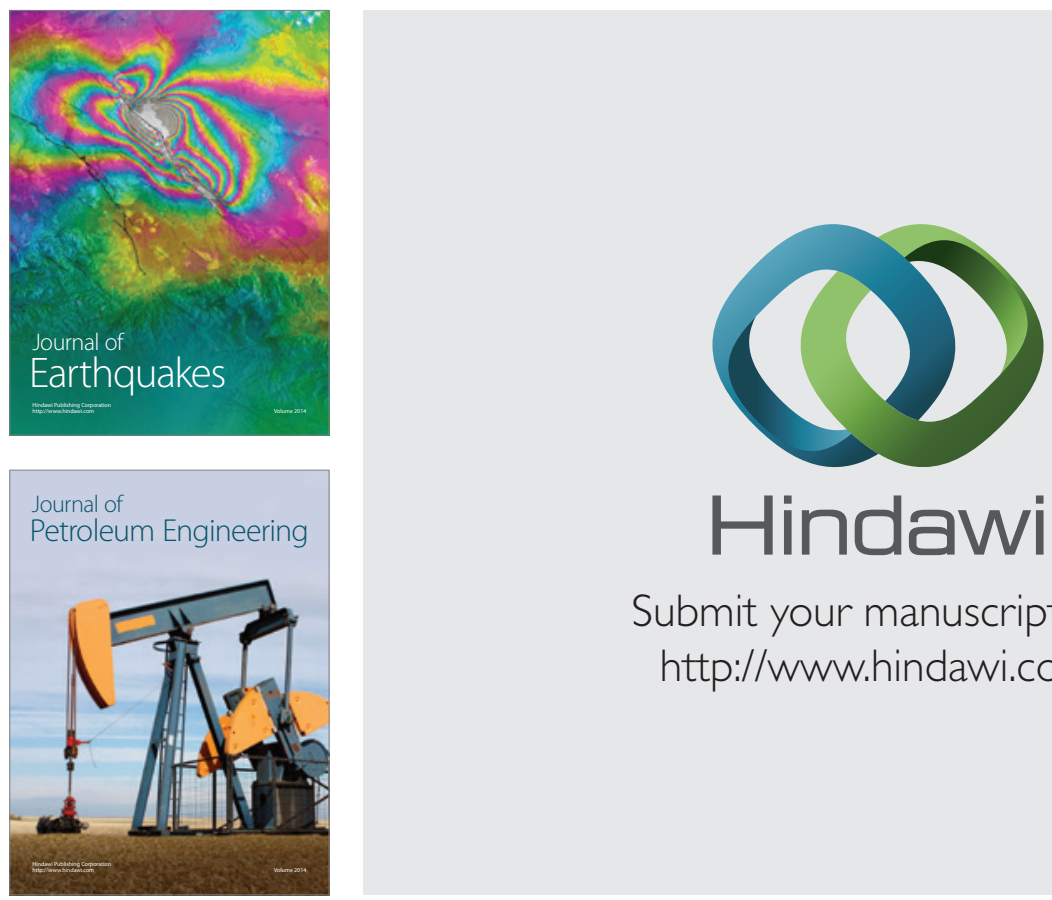

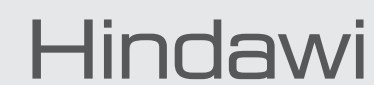

Submit your manuscripts at

http://www.hindawi.com
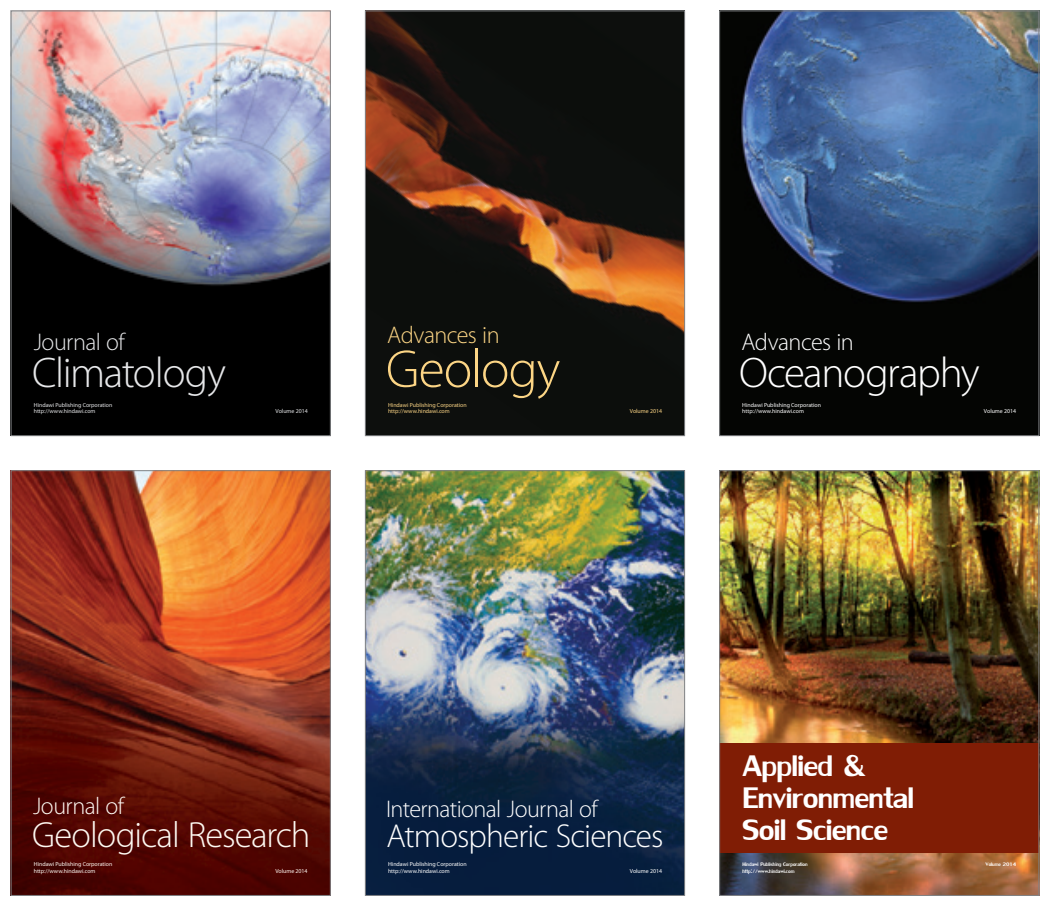
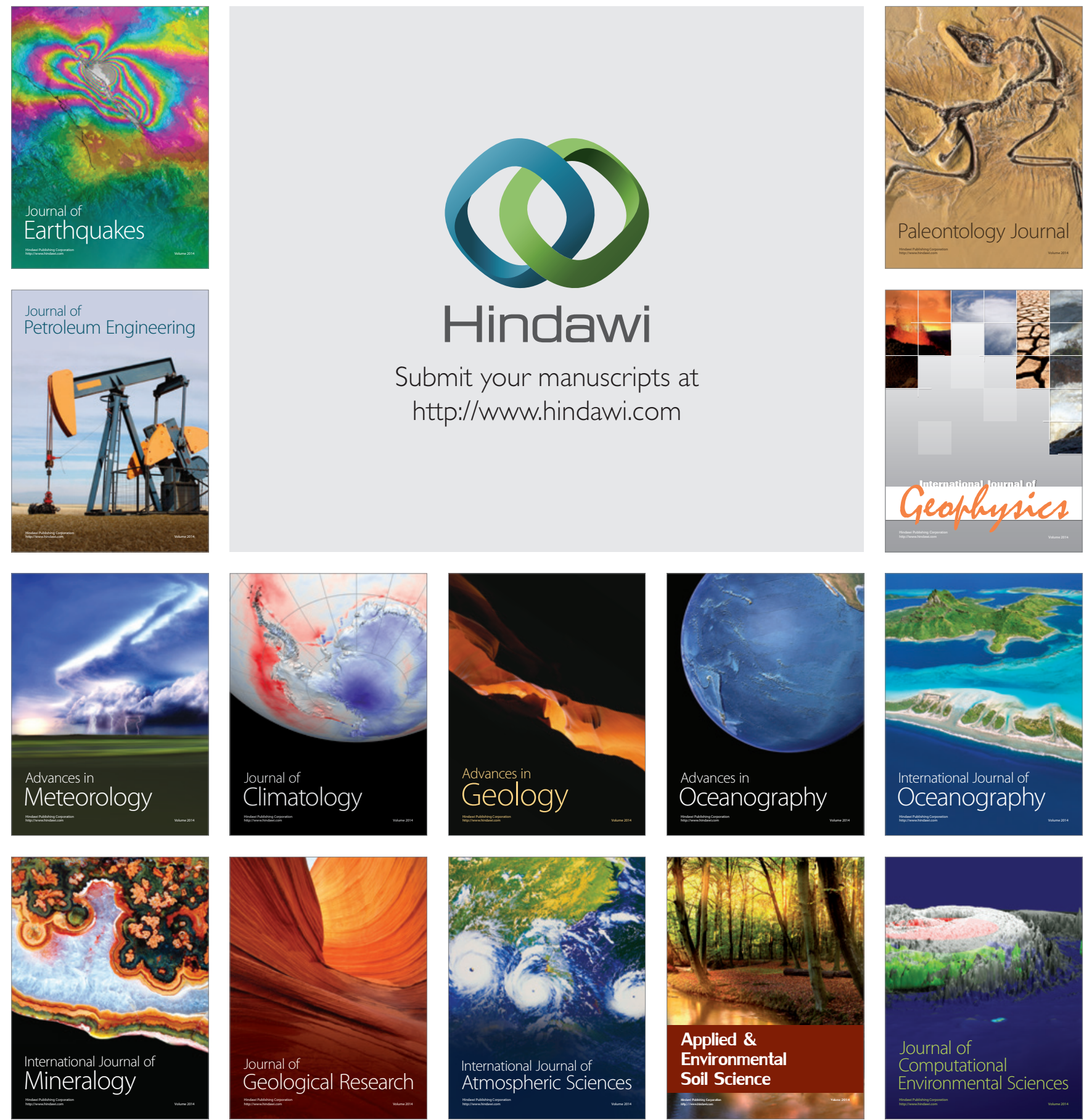